\title{
Pending possible establishment of Littorina littorea in the Pacific: to know the remedy, know thine enemy
}

\author{
Patrik Kraufvelin
}

Received: 20 February 2013/ Accepted: 21 February 2013/Published online: 13 March 2013

(C) Springer-Verlag Berlin Heidelberg 2013

The number of human-mediated marine introductions is constantly growing globally, and whenever a non-indigenous species survives the most critical filters it encounters, such as tolerance to conditions during transport and survival in the new habitat with novel species interactions (Elton 1958; Mack et al. 2000; Lenz et al. 2011; Sareyka et al. 2011), it may become permanently established and in the worst case proceed to impose clearly negative impacts on its new surroundings. One such introduction may be exemplified by the common periwinkle, Littorina littorea, which supposedly was introduced to the NW Atlantic from Europe in the 1840 s as a food source or in rock ballast (Chapman et al. 2007). Now, L. littorea constitutes one of the most abundant mollusks in its invaded NE American range with extensive ecological effects such as reduced recruitment of algae and invertebrates as well as generally altered rocky shore community structure and diversity (see Harley et al. 2013 for references, and Díaz et al. 2012 for more on its effects in its native European range). During the past few decades, L. littorea has also appeared in several locations on the North American Pacific coast (see Harley et al. 2013 for references), although it does not yet seem to be self-recruiting (Chang et al. 2011). This time, the main vector is probably the export of live seafood

Communicated by U. Sommer.

P. Kraufvelin $(\bowtie)$

ARONIA, Coastal Zone Research Team, Åbo Akademi

University and Novia University of Applied Sciences,

Raseborgsvägen 9, 10600 Ekenäs, Finland

e-mail: pkraufve@abo.fi

P. Kraufvelin

Environmental and Marine Biology, Åbo Akademi University,

Artillerigatan 6, 20520 Åbo, Turku, Finland followed by people's diverse reasons (ethical and religious considerations or a personal desire to establish a harvestable resource) for releasing living snails (Harley et al. 2013). Why are then some introductions immediately successful, while others are not? Understanding the factors restricting the establishment of a species is arguable one of the holy grails of invasion biology, and the unique opportunity to focus on a species that seems likely to establish, but has not yet done so, is very exciting from an strictly ecological point of view (e.g. Stachowicz et al. 2002), despite all the possible downsides associated with a permanent establishment.

In their original article, Harley et al. (2013) provides a comprehensive case study of the current status for L. littorea in Vancouver, where L. littorea has been found only at a couple of sites, without detectable community impact, this far. Whenever encountered, the species has been eradicated by the authors and co-workers, and to date, $L$. littorea has not been found again during repeated revisits over the past 1.5 years. Regarding the collected individuals, their morphology and the presence of possible hitchhikers were examined and compared to market snails. The laboratory examination indicated that the field specimens likely originated from the live seafood trade and that cooccurring organisms, living on the gastropod shells and as gut parasites, could still be introduced even if a L. littorea introduction would fail. A set of experiments, focusing on potential future success and impact of L. littorea, like comparing its grazing effects with those of a native gastropod, determining its survival under low salinity and its susceptibility to native predators, rendered significant and interesting results. L. littorea had a similar dietary preference as the native gastropod Chlorostoma funebralis suggesting possible competition. L. littorea was also capable of surviving at seasonal low salinity in the area. Most 
interestingly, the predation experiments showed that $L$. littorea lacked behavioral avoidance responses to local species of predatory sea stars and that sea star predation rates were much higher on $L$. littorea than on native $C$. funebralis in common garden experiments. These latter observations may be a direct reason for the still unsuccessful establishment of L. littorea in the Pacific, and they might also turn up as a thrilling mode of potential biological control (see below).

Although management issues were clearly beyond the scope of the paper by Harley et al. (2013), the currently open situation for L. littorea in the Pacific called for the authors' views about the possible efficiency of measures such as: active removal campaigns (preferably scientifically guided), public information/outreach efforts to increase awareness about the risk of releasing live seafood into the environment, strengthened regulations/legislation, and possibilities for transplanting predators (sea stars) to areas where L. littorea occurs as a form of biological control. To my request about this, Christopher Harley kindly replied (full citation): In terms of preventing the potential invasion, there are at least four ways to supplement the efforts of a rag-tag band of concerned scientists and children (Fig. 1).
One would be to increase the size of the rag-tag band through public outreach activities (organized beach walks, etc.). A second would be through public education (e.g., letters to the editor in local newspapers) aimed at reducing the likelihood of future introductions. Third, steps could be taken to change the live import laws for certain species. Finally, it would be interesting to try native predator enhancements in affected areas. Sea stars may be better at finding periwinkles than humans are, and they would be in the affected area $24 / 7$, not just once per month. I was tempted to try this technique as an experiment, but in the end, I decided that leaving one site as a control was unethical given that (1) eradication appeared possible and (2) the control site could have launched an invasion.

Even though the current status with regard to the introduction and establishment of L. littorea in the Pacific could change quite rapidly, it appears that there are still many sound alternatives available for management (see also Simberloff et al. 2005). Along with the ones listed above, boosting the existing knowledge of L. littorea in the Pacific and elsewhere should be stressed. With regard to this, a thorough reading of the feature article by Harley et al. (2013) is an excellent place to start.

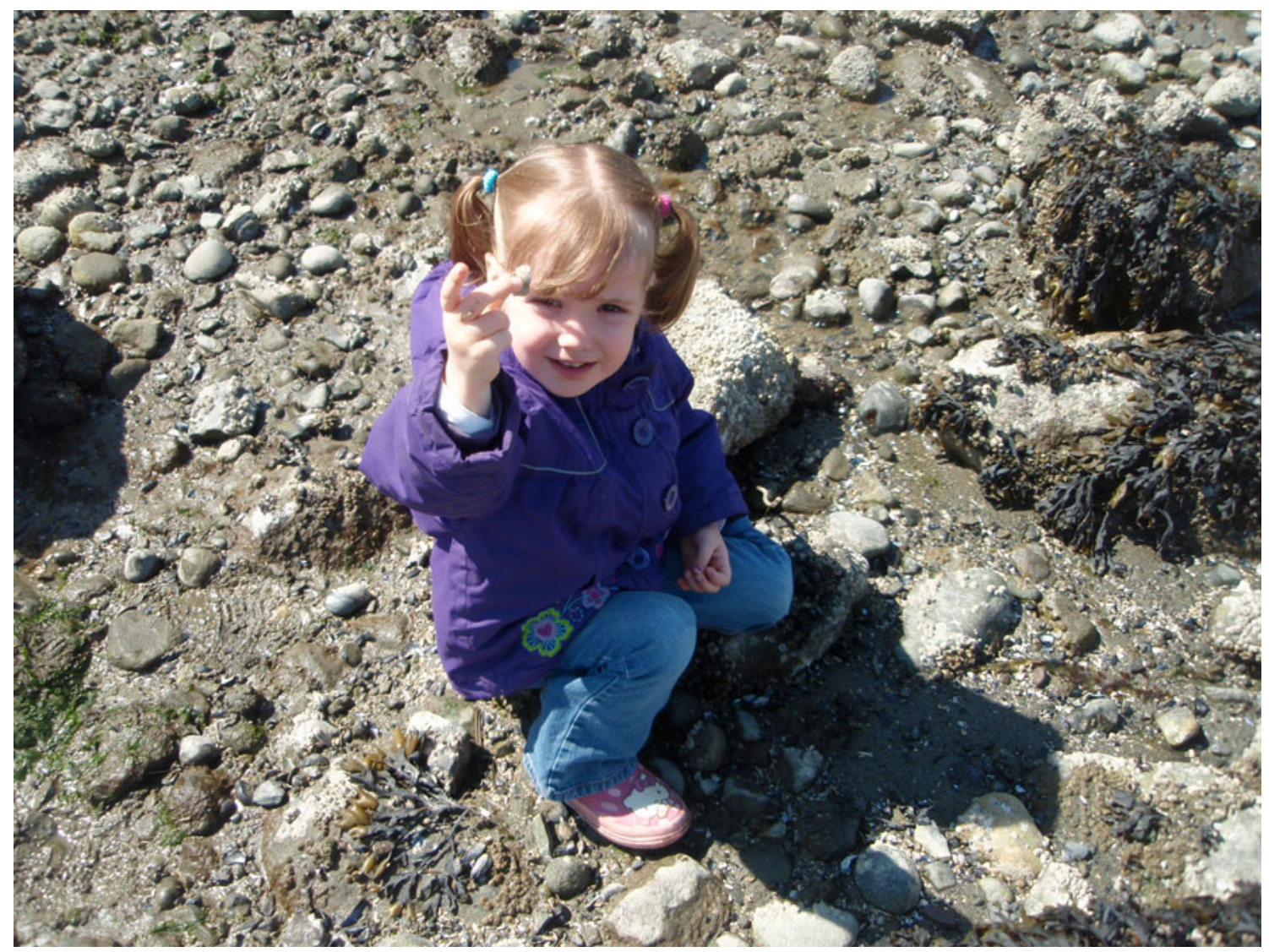

Fig. 1 Preventing possible L. littorea invasion by active removal? Zoe Harley holding up an individual that she has found at Acadia Beach (Photo: Christopher Harley) 


\section{References}

Chang AL, Blakeslee AMH, Miller AW, Ruiz GM (2011) Establishment failure in biological invasions: a case history of Littorina littorea in California, USA. PLoS ONE 6:e16035

Chapman JW, Carlton JT, Bellinger MR, Blakeslee AMH (2007) Premature refutation of a human-mediated marine species introduction: the case history of the marine snail Littorina littorea in the northwestern Atlantic. Biol Invasions 9:737-775

Díaz E, Kraufvelin P, Erlandsson J (2012) Combining gut fluorescence technique and spatial analysis to determine Littorina littorea grazing dynamics in nutrient-enriched and nutrientunenriched littoral mesocosms. Mar Biol 159:837-852

Elton C (1958) The ecology of invasions by animals and plants. Methuen, London

Harley CDG, Anderson KM, Lebreton CA-M, MacKay A, AyalaDiaz M, Chong SL, Pond LM, Amerongen Maddison JH, Hung BHC, Iversen SL, Wong DCM (2013) The introduction of Littorina littorea to British Columbia, Canada: potential impacts and the importance of biotic resistance by native predators. Mar Biol. doi:10.1007/s00227-013-2206-8
Lenz M, da Gama BAP, Gerner NV, Gobin J, Gröner F, Harry A, Jenkins SR, Kraufvelin P, Mummelthei C, Sareyka J, Xavier E, Wahl M (2011) Non-native marine invertebrates are more tolerant towards environmental stress than taxonomically related native species: results from a globally replicated study. Environ Res 111:943-952

Mack RN, Simberloff D, Lonsdale WM, Evans H, Clout M, Bazzaz FA (2000) Biotic invasions: causes, epidemiology, global consequences, and control. Ecol Appl 10:689-710

Sareyka J, Kraufvelin P, Lenz M, Lindström M, Tollrian R, Wahl M (2011) Differences in stress tolerance and brood size between a non-indigenous and an indigenous gammarid in the northern Baltic Sea. Mar Biol 158:2001-2008

Simberloff D, Parker IM, Windle PN (2005) Introduced species policy, management, and future research needs. Front Ecol Environ 3:12-20

Stachowicz JJ, Fried H, Osman RW, Whitlatch RB (2002) Biodiversity, invasion resistance, and marine ecosystem function: reconciling pattern and process. Ecology 83:2575-2590 